Article

\title{
An Innovative Porous Nanocomposite Material for the Removal of Phenolic Compounds from Aqueous Solutions
}

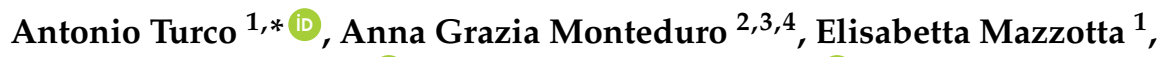 \\ Giuseppe Maruccio ${ }^{2,3}$ (D) and Cosimino Malitesta ${ }^{1}$ (D) \\ 1 Dipartimento di Scienze e Tecnologie Biologiche ed Ambientali (Di.S.Te.B.A.), Università del Salento, \\ via Monteroni, 73100 Lecce, Italy; elisabetta.mazzotta@unisalento.it (E.M.); \\ cosimino.malitesta@unisalento.it (C.M.) \\ 2 CNR NANOTEC - Institute of Nanotechnology c/o Campus Ecotekne, Via Monteroni, 73100 Lecce, Italy; \\ annagrazia.monteduro@unisalento.it (A.G.M.); giuseppe.maruccio@unisalento.it (G.M.) \\ 3 Dipartimento di Matematica e Fisica, Università del Salento, Via per Arnesano, 73100 Lecce, Italy \\ 4 National Institute of Gastroenterology “S. De Bellis” Research Hospital, via Turi 27, 70013 Castellana Grotte, \\ Bari, Italy \\ * Correspondence: antonio.turco@unisalento.it; Tel.: +39-0832-29-7041
}

Received: 3 May 2018; Accepted: 14 May 2018; Published: 16 May 2018

\begin{abstract}
Energy efficient, low-cost, user-friendly, and green methods for the removal of toxic phenolic compounds from aqueous solution are necessary for waste treatment in industrial applications. Herein we present an interesting approach for the utilization of oxidized carbon nanotubes (CNTs) in the removal of phenolic compounds from aqueous solution. Dried pristine CNTs were stably incorporated in a solid porous support of polydimethylsiloxane (PDMS) facilitating the handling during both oxidation process of the nanomaterial and uptake of phenolic compounds, and enabling their safe disposal, avoiding expensive post-treatment processes. The adsorption studies indicated that the materials can efficiently remove phenolic compounds from water with different affinities towards different phenolic compounds. Furthermore, the adsorption kinetics and isotherms were studied in detail. The experimental data of adsorption fitted well with Langmuir and Freundlich isotherms, and pseudo-second-order kinetics, and the results indicated that the adsorption process was controlled by a two-step intraparticle diffusion model. The incorporation of CNTs in polymeric matrices did not affect their functionality in phenol uptake. The material was also successfully used for the removal of phenolic compounds from agricultural waste, suggesting its possible application in the treatment of wastewater. Moreover, the surface of the material could be regenerated, decreasing treatment costs.
\end{abstract}

Keywords: carbon nanotubes; phenol; phenolic compound; remediation; oil mill wastewater

\section{Introduction}

Petrochemical, pharmaceutical, steel, and agricultural industries produce a huge number of phenol and phenolic compounds, which are common contaminants in industrial wastes [1]. Due to their toxicity and carcinogenicity, many of these kinds of compounds have been classified as hazardous pollutants [2]. Exposure to phenolic compounds, even at low concentrations and short-term exposure, leads to high irritation to eyes, skin, and mucous, and causes headache and dizziness. Long-term exposure results in high blood pressure and severe liver and kidney damage.

Different technologies, like electrochemical oxidation [3-5], (electro)chemical coagulation [6-8], solvent extraction [9,10], bioremediation [11-13], and photocatalytic degradation [14-16], have been 
developed in the years to remove phenolic compounds from wastewater, however, all these methods require high energy input and/or additional chemicals, making the treatment expensive. Moreover, secondary pollutants are often generated during the treatment process. Thus, there is a need to develop energy efficient and low-cost methods to separate/remove phenolic compounds from aqueous wastes. In this view, adsorption techniques can offer an attractive alternative. Several adsorbents, such as nanoparticles [17,18], activated carbon [19-21], resins [22-24], and other low-cost adsorbents [25], have been used for removal of phenolic compounds. Carbon nanotube (CNT) materials have demonstrated good potential for adsorption of phenols from aqueous solutions [26-28]. Their large surface area, porosity, and functional groups are features that can enhance their adsorption efficiency [29]. However, although these materials showed good affinity towards phenolic compounds, the major limit in their application is that collection of the carbon nanotube powder after the remediation process is cumbersome, and require post-processes, such as filtration with membrane with nanometer size pores and/or centrifugation, thus limiting their real and large-scale application. Fixing the CNT powder in an easy way in solid compact without compromising the chemical affinity to phenols could be an interesting solution for the usability in the treatment of wastewater. Herein, we report an approach to utilizing carbon nanotubes immobilized on a porous polydimethylsiloxane (PDMS) sponge for the removal of phenolic compounds. The PDMS acts as a support for CNTs and its microporous structure permits it to have a high amount of nanomaterial on the sponge surface in a reduced volume. The as-prepared material can remove different phenolic compounds with different affinities, depending on the type and number of functional groups present as substituents on the aromatic benzenic ring of phenols.

The adsorption mechanisms and kinetics were studied through different theoretical models. The system was demonstrated to be effective in the purification of complex matrices, such as oil mill wastewater, an agricultural waste obtained after oil production. The composite foams have good performance, but most importantly, they can be easily handled and disposed. The material recyclability is also demonstrated, making the system an effective and low-cost method for phenol adsorption from aqueous wastewater.

\section{Materials and Methods}

\subsection{Materials}

The PDMS Prepolymer Kit (Sylgard 184), comprising monomer and curing agent, were purchased from Dow Corning, Midland, MI, USA. Multiwalled carbon nanotubes (MWNTs) with a diameter of $25.4 \pm 4 \mathrm{~nm}$ (see Figure S1) were provided by Nanostructured and Amorphous Materials, Inc., Los Alamos, NM, USA. All the other reagents were purchased from VWR International srl, Milano, Italy, and used as received. Olive mill wastewater was collected from a three phase continuous extraction unit, Miggiano, Lecce, southern Italy. All the solutions were prepared with ultrapure water

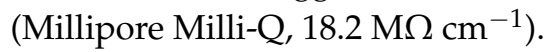

\subsection{Fabrication of PDMS/MWNT Porous Nanocomposite}

Porous PDMS/MWNT nanocomposite was prepared according to a modified procedure previously developed by our group [30]. Briefly, glucose particles were mixed for $30 \mathrm{~min}$ with MWNTs at $3 \% w / w$ under dry conditions at room temperature, in a propylene centrifuge tube, thus allowing the adsorption of carbon nanotubes on glucose microparticle surface without the need for other reagents. In particular, as previously reported, sugar crystals could mechanically break the $\pi-\pi$ stacking between the MWNTs favoring the disruption of the bundles, and the adsorption of the nanomaterials on glucose crystal surfaces [30]. On the top of the mixture, an appropriate amount of PDMS prepolymer and curing agent in the ratio of 10:1 diluted at $40 \% \mathrm{in} w \mathrm{t}$, in hexane, was added. The mixture was then centrifuged at $8000 \mathrm{rpm}$ for $20 \mathrm{~min}$ to pack glucose crystals and promote the infiltration of the prepolymerization mixture among the sugar templates. The as-obtained composites 
were then cured at $60^{\circ} \mathrm{C}$ overnight to accomplish polymerization. The cured sample was removed from the centrifuge tube and soaked in boiling water to dissolve glucose microparticles, and then sonicated with warm water and ethanol to remove residual template microparticles, and not entrapped MWNTs.

\subsection{Oxidation of PDMS/MWNT Porous Nanocomposite}

As-prepared PDMS/MWNT porous nanocomposite was placed in water under reduced pressure to saturate all the cavities of the material with water. Then, concentrated $\mathrm{HNO}_{3}$ was added drop by drop to the solution, until a concentration of $3 \mathrm{M}$ was reached. The reaction was kept at room temperature for $2 \mathrm{~h}$. The PDMS/MWNT sponge was removed from the solution and washed repetitively with water until the $\mathrm{pH}$ of the washing solution become neutral, and dried under vacuum. After that, the nanocomposite material was dipped in $\mathrm{H}_{2} \mathrm{O}_{2} 30 \% w / w$ for $2 \mathrm{~h}$, and then washed three

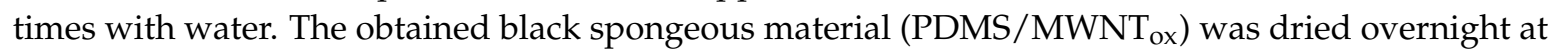
$60{ }^{\circ} \mathrm{C}$.

\subsection{Characterization Techniques}

The morphological characterization of PDMS and PDMS-CNT sponge samples was performed using a scanning electron microscope (SEM, Carl Zeiss Merlin, Jena, Germany) in top view configuration, and applying an acceleration voltage of $3 \mathrm{kV}$ for PDMS sponges and $5 \mathrm{kV}$ for PDMS-CNT samples. Secondary electron and in-lens detectors were employed for low and high magnification, respectively. Morphological characterization of as-received MWNTs was performed using a transmission electron microscope (TEM, Philips EM208, Philips Scientifics, Eindhoven, The Netherlands) applying an acceleration voltage of $100 \mathrm{kV}$.

XPS measurements were performed in triplicate with an AXIS ULTRA DLD (Kratos Analytical, Manchester, UK) electron spectrometer using a mono-Al K $\alpha$ source (1486.6 eV) operating at $225 \mathrm{~W}$ $(15 \mathrm{kV}, 15 \mathrm{~mA})$. Survey scan spectra were recorded using a pass energy of $160 \mathrm{eV}$ and a $1 \mathrm{eV}$ step. The hybrid lens mode was used for all measurements. In each case, the area of analysis was about $700 \mu \mathrm{m}$ $\times 300 \mu \mathrm{m}$. The base pressure in the analysis chamber was $2 \times 10^{-9}$ Torr. During the acquisitions, a system of neutralization of the charge was used. The binding energy (BE) scale was referenced to the C 1s line of alkylic carbon (285 eV). Processing of the spectra was accomplished with CasaXPS Release 2.3.16 software (Casa Software Ltd., Teignmouth, UK).

\subsection{Phenol Determination}

Quantitative determination of the concentration of the phenolic compounds was performed by UV-vis spectrophotometry using a Cary UV 50 spectrophotometer. The calibration curves (absorbance vs. concentration) for each tested phenolic compound were obtained at their maximum absorption wavelength. Since analytical wavelength and sensitivity for phenolic compounds are affected by the solution $\mathrm{pH}$, calibration curves were obtained at the same $\mathrm{pH}$ of the adsorption experiments ( $\mathrm{pH}$ adjusted with $\mathrm{NaOH}$ or $\mathrm{HCl}$ ).

\subsection{Adsorption Experiments}

For the adsorption studies, $5 \mathrm{~mL}$ of aqueous solution at $\mathrm{pH}=10$ with phenolic compounds were prepared at different concentrations, which are reported in the different results and discussion sections.

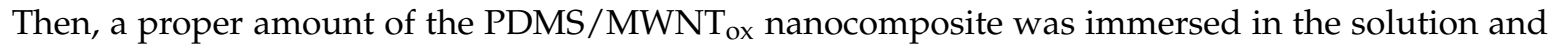
shacked at room temperature for $24 \mathrm{~h}$. Small aliquots were collected from the solution at specific time intervals, namely $0.5,1,1.5,2,2.5,3,4,20$, and $24 \mathrm{~h}$ (if not otherwise indicated), for further spectrophotometric analysis. The time dependent removal efficiency and the equilibrium adsorption capacity of the sponges were calculated by Equations (1) and (2), respectively:

$$
\text { removal efficiency }(\%)=\left[\frac{\left(C_{0}-C_{t}\right)}{C_{0}}\right] \times 100
$$




$$
\text { adsorption capacity, } q_{e}\left(\frac{m g}{g}\right)=\left[\frac{\left(C_{0}-C_{e}\right)}{W}\right] \times V
$$

Here, the following abbreviations were applied: $C_{0}$ is the initial concentration of phenolic compounds in ppm $(\mathrm{mg} / \mathrm{Kg}), C_{t}$ is the concentration expressed in ppm at a given time $t$ (hours), $q_{e}$ is the adsorption capacity $\left(\mathrm{mg} / \mathrm{g}\right.$ ) at the equilibrium, $C_{e}$ is the phenolic compound concentration expressed in ppm at the equilibrium conditions (usually after $20 \mathrm{~h}$ ), $V$ is the volume of the solution in liters, and $W$ is the weight of the sponge in grams.

\subsection{Removal of Phenolic Compound from Olive Mill Wastewater (OMW)}

OMW were obtained from a three-phase continuous extraction unit from Miggiano, Lecce (southern Italy). The OMW samples were first stored in a polyethylene tube at ambient temperature. PDMS $/ \mathrm{MWNT}_{\text {ox }}(1.2 \%$ in weight) were added to OMW and shacked with a rotary shaker, and aliquots were collected from the solution after $24 \mathrm{~h}$ for further spectrophotometric analysis. Concentration of phenols in OMW was determined by the colorimetric reaction with Folin-Ciocalteu reagent. Briefly $50 \mu \mathrm{L}$ of the OMW was mixed with $250 \mu \mathrm{L}$ of Folin-Ciocalteu reagent, $240 \mu \mathrm{L}$ of water, and $2.5 \mathrm{~mL}$ of a solution of $\mathrm{NaHCO}_{3}(7 \% \mathrm{w} / \mathrm{w})$, and the mixture was shaken for $90 \mathrm{~min}$ in dark. The blue color formed was measured at $760 \mathrm{~nm}$. The phenolic compound concentration of OMW samples, as determined by the Folin-Ciocalteu method, were reported as caffeic acid equivalents by reference to a standard curve [31].

\section{Results}

\subsection{Preparation and Characterization of PDMS/MWNTs Sx $_{\text {Spongeous Material }}$}

Porous PDMS/MWNT sponges were fabricated by polymerization of the prepolymer and the curing agent in hexane in the presence of glucose microparticles covered with MWNTs. The color of the as-obtained materials was black, indicating the presence of MWNTs as filler in the as prepared sponge (Scheme 1).

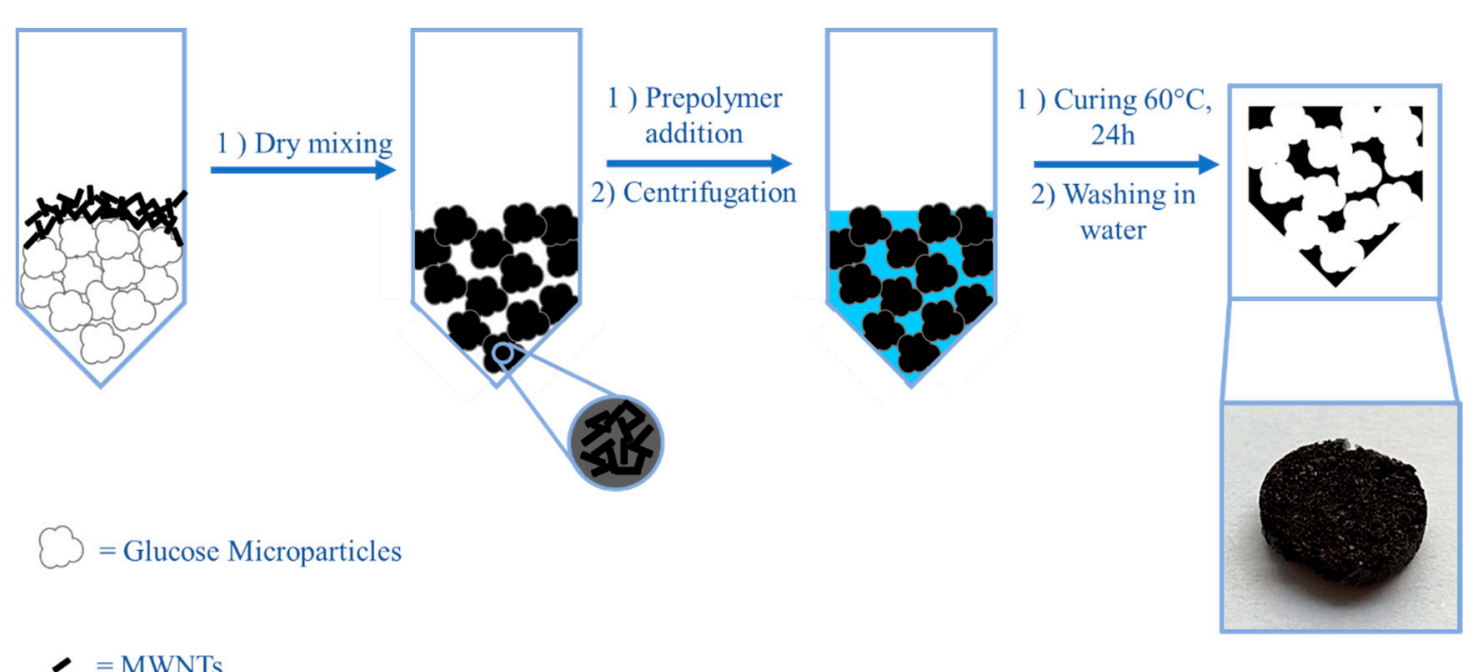

Scheme 1. Schematic representation of the preparation of the polydimethylsiloxane (PDMS)-multiwalled carbon nanotube (MWNT) sponge, and photograph of the as-obtained material.

The as-prepared sponges were then chemically oxidized with a mild treatment based on nitric acid, followed by hydrogen peroxide to increase the number of $-\mathrm{OH},-\mathrm{C}=\mathrm{O}$, and $-\mathrm{COOH}$ groups on the MWNT surface, minimizing the nanotube damage [32]. The oxidation process, including post-treatment procedure (see Section 2) were facilitated by the fact that MWNTs are entrapped in 
a macroscopic polymeric structure, thus speeding-up the procedure, avoiding time expensive steps, such as filtration and/or centrifugation.

The effective functionalization of MWNTs was verified by XPS. The survey scan spectra in Figure 1 reveal the chemical composition of the uppermost surface of the PDMS/MWNT spongeous material before (blue curve) and after (grey curve) the mild oxidation treatment. The major peaks observed in the spectra were due to $\mathrm{C}, \mathrm{O}$, and $\mathrm{Si}$ photoelectron peaks. The $\mathrm{O} 1 \mathrm{~s} / \mathrm{C} 1 \mathrm{~s}$ ratio before the mild acidic treatment was equal to $0.57 \pm 0.01$. After the oxidation process, the peak relative to $\mathrm{O} 1 \mathrm{~s}$ photoelectron became more prominent, and $\mathrm{O} 1 \mathrm{~s} / \mathrm{C}$ 1s ratio increased to $2.11 \pm 0.31$, indicating that oxygen-containing moieties were present on the surface of the nanocomposite material [33]. Moreover, iron photoelectron peaks are not evident on both samples, thus suggesting the low metallic content of MWNTs, as also clearly visible in the TEM image of the as-received MWNTs (Figure S1).

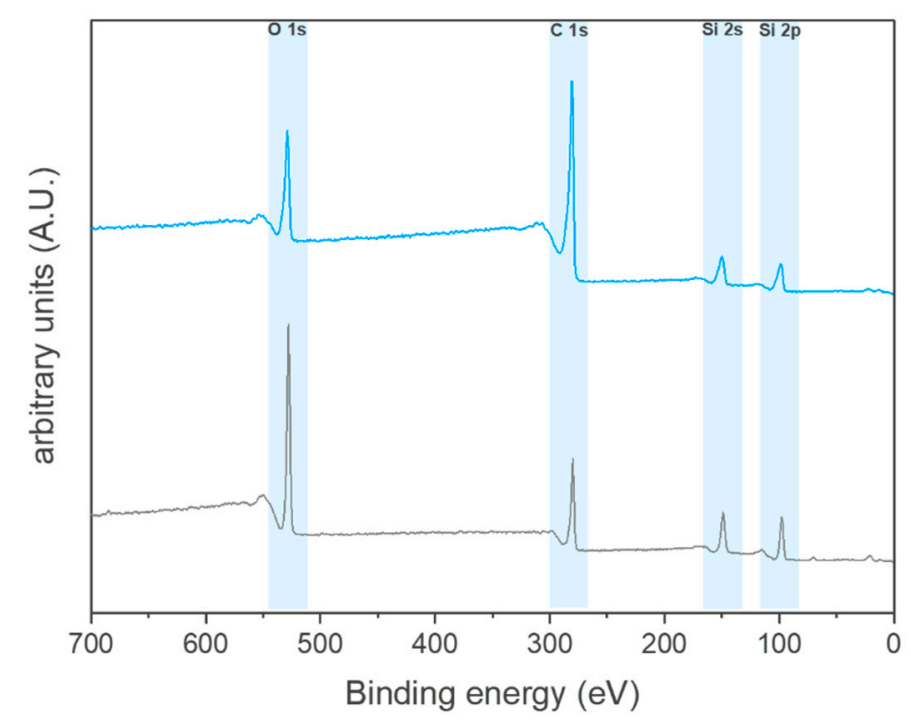

Figure 1. XPS survey spectra of PDMS/MWNT sponge before (blue curve) and after (grey curve) mild oxidation treatment.

SEM images (Figure 2a-c) of PDMS/MWNT ox sponge cross-sections evidence an interconnected $3 \mathrm{D}$ framework. Figure $2 \mathrm{~d}$ shows the pore size distribution, which has an average pore dimension of $290 \pm 170 \mu \mathrm{m}$. At higher magnification, the sponges exhibit the presence of the nanomaterial close to the surface of the pores (Figure 2c) with oxidized MWNTs homogenously dispersed inside the polymeric matrices with random orientation.

The amount of $\mathrm{MWNT}_{\mathrm{ox}}$ per gram of sponge were estimated to be $68.7 \mathrm{mg}$, by comparing the

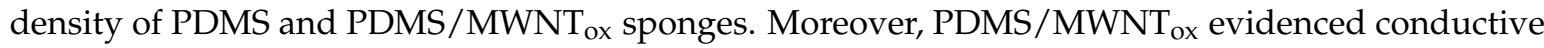
behavior if contacted with a multimeter (Figure S2), thus confirming the presence of a continuous carbonaceous network, the partial integrity of aromatic continuity in $\mathrm{MWNTs}_{\mathrm{ox}}$ inside polymeric matrices, and the presence of $\mathrm{MWNTs}_{\mathrm{ox}}$ on the top layer of the sponge, thus suggesting the possibility of the nanomaterial to interact with molecules in a solution in contact with the surface of the nanocomposite. 


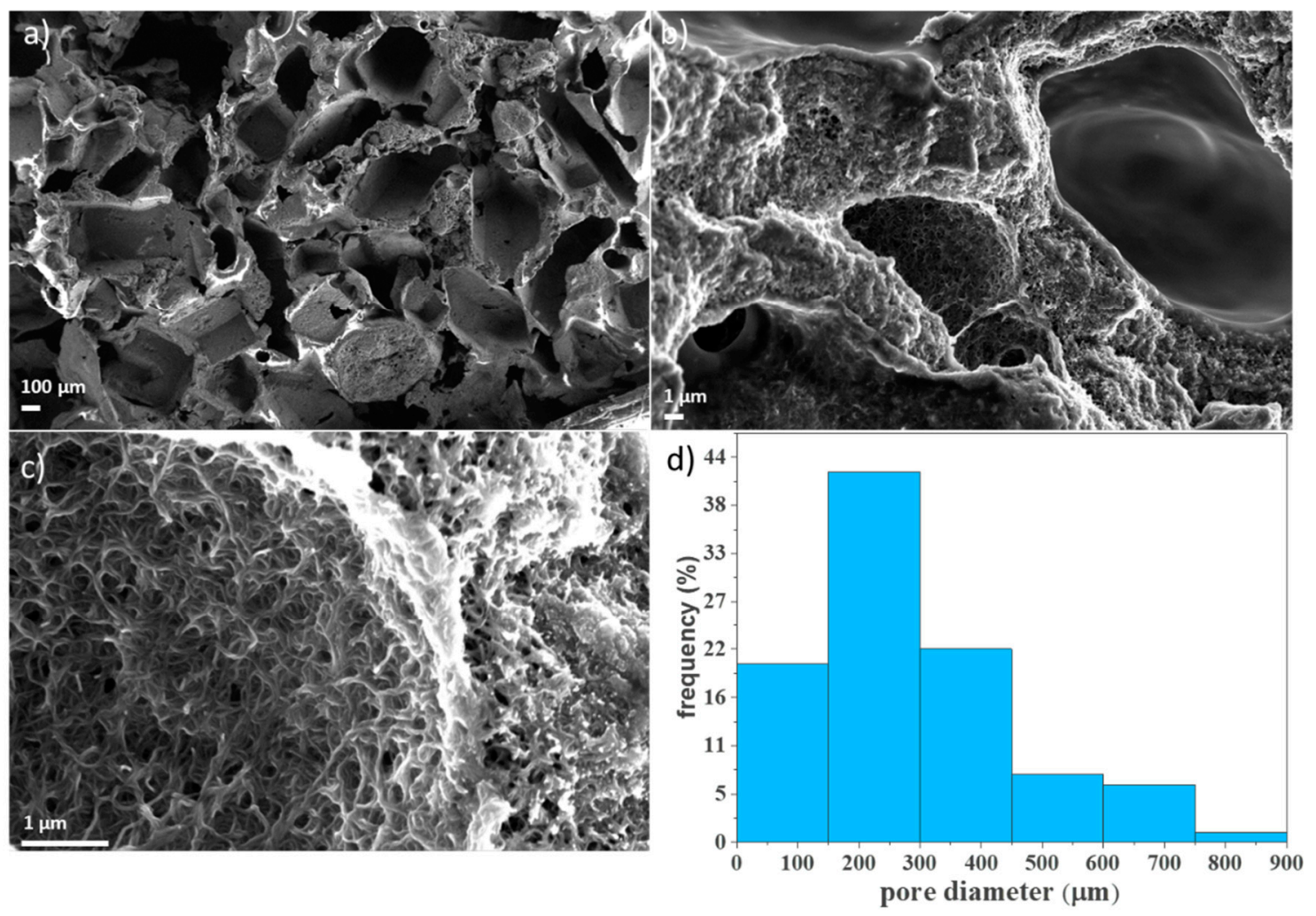

Figure 2. SEM images of porous PDMS/MWNTox sponge at different magnification $(\mathbf{a}-\mathbf{c})$. In (d) pore size distribution is reported.

\subsection{Adsorption of Phenolic Compounds to PDMS/MWNT ox Porous Nanocomposite}

The PDMS/MWNT ${ }_{\text {ox }}$ nanocomposite were dipped in water solutions containing different phenolic compounds at the same concentration for $24 \mathrm{~h}$, and the removal efficiency was calculated as described in the Section 2. Results are summarized in Figure 3. It is important to note that during the process, neither desorption of MWNTs from the polymeric matrices nor damage of the material were observed by naked eye. Although all the phenolic compounds were at the same concentration (i.e., $0.18 \mathrm{mM})$, the removal efficiency $(\mathrm{Q} \%)$ is significantly different for each phenolic compound, suggesting different affinities of the spongeous materials towards the different phenolic compounds. The phenolic compounds used in this study can be classified into two groups: (1) nitroaromatic compound (i.e., 4-nitrophenol), (2) polar aromatic phenolic compounds (i.e., phenol, catechol, bisphenol-A, and 2-aminophenol). Nitroaromatic phenolic compound adsorbed more strongly than polar aromatic compounds, and adsorption of polar aromatic phenolic compounds is influenced by the number and the type of functional groups. For example, adsorption of catechol is slightly higher than phenol and 2-aminophenol adsorbed more than catechol. These results are in agreement with the adsorption behavior of different phenolic compounds on MWNTs previously observed [27]. The different removal efficiencies recorded on PDMS/MWNT ${ }_{\text {ox }}$ sponges depending on the type and the number of functional groups could suggest different interaction mechanisms between phenols and the nanocomposite. 


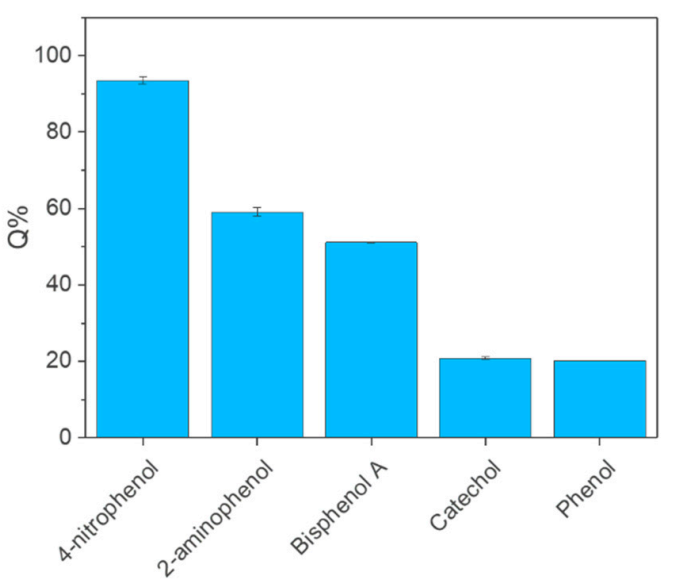

Figure 3. Removal efficiency (Q\%) of different phenols for PDMS/MWNT $\mathrm{Mx}_{\text {sponge. }}$

Nitroaromatic compounds are highly polar, and act as strong electron acceptors when interacting with adsorbents containing structures with high electron polarizability. The other tested phenolic compounds are highly polar but non-electron acceptors. It appears that the higher adsorption of 4-nitrophenol (4-NP) was due to $\pi-\pi$ electron donor-acceptor interactions between the nitroaromatic ( $\pi$-acceptors) and the surface of PDMS/MWNT ${ }_{\text {ox }}$ with regard to graphitic surface ( $\pi$ donors) of carbon nanotubes. The $\pi-\pi$ electron donor-acceptor is a specific, non-covalent interaction that can be established between electron-rich and electron poor moieties. Donor strength increases with the electron-donating ability of substitutes or $\pi$ system polarizability. Acceptor strength is dependent on electron-withdrawing ability and the number of substitutes. The graphitic surface of MWNTs is highly polarizable, and acts as an electron donor when in contact with acceptors, such as nitroaromatic compounds [28]. As an alternative adsorption mechanism, $\mathrm{H}$ bonding between nitro groups ( $\mathrm{H}$ acceptor) and functional groups (e.g., $-\mathrm{COOH},-\mathrm{CO},-\mathrm{CHO}$ ) on the $\mathrm{MWNT}_{\text {ox }}$ surface inside the sponges might also be considered. In this case, the removal efficiency of 4-nitrophenol would increase with decreasing $\mathrm{pH}$, due to the transition of oxidized multiwalled carbon nanotube moieties, such as $-\mathrm{COO}^{-}$to the protonated form, $-\mathrm{COOH}$, that can form H-bonds with nitro group of 4-NP. However, adsorption studies at different $\mathrm{pH}$ showed that when varying $\mathrm{pH}$ from 4 to 11 (Figure S3), the adsorption increases more than $30 \%$, reaching a maximum at $\mathrm{pH} \sim 10$, in which all carbon nanotubes functional groups are mostly in the deprotonated form. Therefore, $\pi-\pi$ electrons-donor-acceptor interactions of nitrophenolic compounds with PDMS/MWNT ox sponges could be the most plausible mechanism of adsorption.

Similarly, two adsorption mechanisms, i.e., $\pi-\pi$ electron donor-acceptor interactions or H-bonding, can be hypothesized in the case of polar organic compounds. With the aim to evaluate the occurring adsorption mechanism, the $\mathrm{pH}$ effect on the sorption of phenol $(\mathrm{Ph})$ by $\mathrm{PDMS} / \mathrm{MWNT}_{\text {ox }}$ sponge was evaluated, with $\mathrm{pH}$ ranging from $\sim 2$ to $\sim 11$. Phenol was chosen because it is the aromatic phenolic compound with lower removal efficiency and simpler chemical composition. As evident (Figure S4), the removal efficiency increases with $\mathrm{pH}$ increase reaching the maximum at $\mathrm{pH} \sim 11$. For higher $\mathrm{pH}$, we observed a dramatic decrease in removal efficiency due to the increased electrostatic repulsion between the dissociated phenol ( $\mathrm{pKa} \sim 10$ ) and negatively charged PDMS/MWNT $\mathrm{Ox}_{\text {ox }}$ surface at these $\mathrm{pH}$ values. The dissociation of $-\mathrm{OH}$ groups on phenol may inhibit the formation of hydrogen bonds between the polar aromatic compound and MWNT surface at higher $\mathrm{pH}$ [27]. However, the increase of the removal efficiency of phenol of about $20 \%$ at $\mathrm{pH} \sim 11$ suggested the low significative involvement of hydrogen bonding between phenol and $\mathrm{PDMS} / \mathrm{MWNT}_{\mathrm{ox}}$ sponge. As already reported in literature, the increasing $\mathrm{pH}$ may alter the properties of polar aromatics, such as $\pi$-donating strength, thus increasing their adsorption affinities to the $\mathrm{MWNT}_{\mathrm{ox}}$ surface [27]. However, the mechanism of this process is still unknown. Therefore, the adsorption mechanism for phenol could be also attributed to $\pi-\pi$ electron 
donor-acceptor interaction. In more detail, hydroxyl is an electro-donating functional group which can increase the $\pi$ donating strength of the host aromatic ring. The MWNTs $\mathrm{Mx}_{\mathrm{ox}}$ on the surface of PDMS sponge can act as electron acceptors, favoring adsorption of phenol on the surface with an opposite behavior with respect to that observed for nitroaromatic compound adsorption. It is well known, in fact, that the graphene surface of MWNTs could be highly polarizable, and may act as an amphoteric adsorbent attracting $\pi$-acceptor to the electron-rich graphene surface area near edges, and $\pi$-donors to the central regions, being relatively electron poor [27].

The proposed mechanism can be easily translated to the increase in removal efficiency for catechol due to the presence of two hydroxyl groups that can increase donor strength of aromatic benzene. Moreover, the removal efficiency could also increase if a $-\mathrm{OH}$ group of catechol is substituted with an amino group, due to the higher electron-donating effect of amino group with respect to hydroxyl [34]. The increased removal efficiency for bisphenol A, with respect to phenol and catechol, could be explained both by the $\pi-\pi$ electron donor-acceptor interaction, and by the fact that larger molecules can twist themselves so that they match with the curvature surface, thus forming more stable complexes with the $\mathrm{MWNT}_{\text {ox }}$ surface [29].

To better characterize the adsorption properties of the nanocomposite material, the same amount of sponge was dipped in two different solutions containing the phenolic compounds, for which the material has demonstrated the highest and lowest removal efficiencies, namely 4-nitrophenol and phenol. As observable in Figure 4, in both cases the concentration of phenolic compounds decreases with time until a plateau is reached (e.g., $20 \mathrm{~h}$ ). It is interesting to note that more than $90 \%$ of the total removal efficiency is reached after $\sim 3.3 \mathrm{~h}$ for both the phenolic compounds, suggesting a relatively fast adsorption process. Figure 4 also reported adsorption kinetic studies for sponges made of PDMS (green square) and PDMS/MWNTs (blue triangle), for which the oxidation process was not performed before the exposure to 4-nitrophenol. In these cases, the uptake of nitroaromatic compound was not detectable, suggesting that PDMS acts only as a support for MWNT deposition, without affecting removal efficiency. Moreover, the oxidation of MWNTs on porous PDMS surface appears to be necessary for adsorption of 4-nitrophenol. It is well known in literature that for polar organic compounds, such as phenols, the adsorption tends to increase with increased CNT oxygen content, due to both enhanced electron donor-acceptor interactions and the depressed hydrophobic interaction [29]. Moreover, the low amount of oxygen moieties on entrapped MWNT surfaces before oxidation could avoid the diffusion of water inside polymeric matrices, due to the high hydrophobicity of both PDMS and MWNTs [34,35]. Similar results were also obtained in the case of phenol adsorption for a PDMS and PDMS/MWNT sponge.

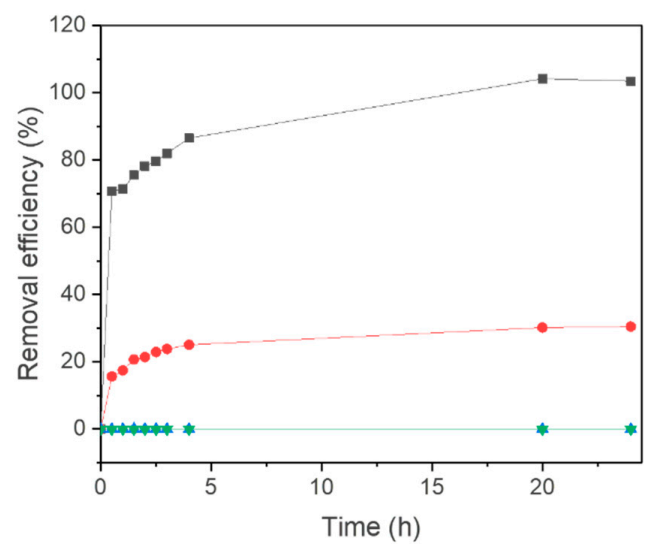

Figure 4. Time dependent removal efficiency (\%) of 4-nitrophenol by the PDMS/MWNT ${ }_{\text {ox }}$ sponge (gray square), PDMS sponge (green square), and PDMS/MWNT sponge (blue triangle). The time dependent removal efficiency (\%) of the phenol by the PDMS/MWNT ${ }_{\text {ox }}$ sponge is also reported (red circle). 
Figure 5 reports the removal efficiency of 4-nitrophenol and phenol for different initial concentrations. As evident in both cases, as the initial phenolic concentration increases, the removal efficiency is reduced, indicating that the concentration of the species in solution is much higher compared to that of the phenolic compounds that can be adsorbed by the nanocomposite materials.
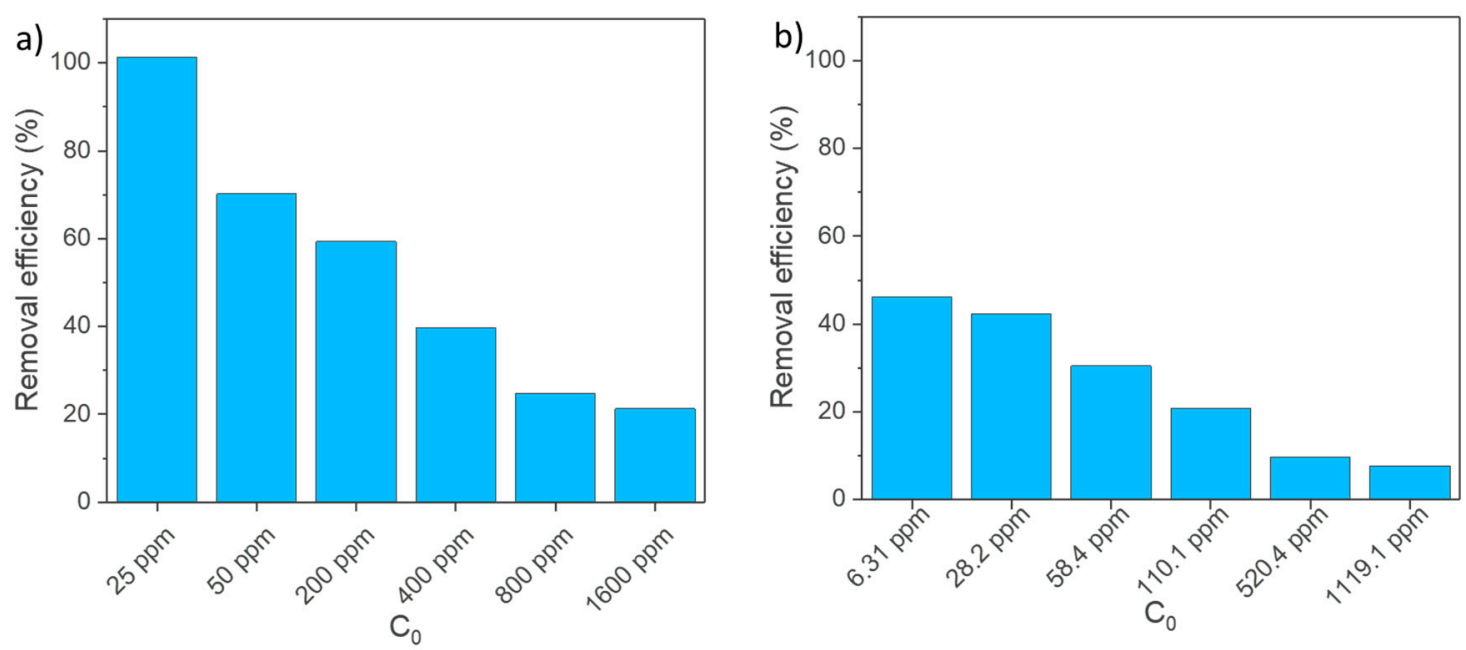

Figure 5. Effect of the initial 4-NP (a) and Ph (b) concentration on the removal efficiency (\%).

\subsection{Adsorption Isotherms}

Adsorption involves the accumulation of substances at an interface between the solid surface and the bathing solution. The equilibrium relationship between sorbent and sorbate are described by adsorption isotherms, that usually represent the ratio between the adsorbed quantity and that remaining in solution at a fixed temperature at equilibrium. In order to optimize the design of a sorption system, it is important to establish the most appropriate correlation for the equilibrium curve. An equilibrium is established when the amount of sorbate being adsorbed is equal to the amount being desorbed. Different isotherm equations are available in literature, and two of the most important isotherms, namely the Langmuir and Freundlich isotherms, are selected for this study.

The Langmuir equation is represented as follows:

$$
q_{e}=\frac{K_{L} q_{\max } C_{e}}{1+K_{L} C_{0}}
$$

where $q_{e}(\mathrm{mg} / \mathrm{g})$ and $C_{e}(\mathrm{~g} / \mathrm{L})$ are the amount of adsorbed phenolic compounds per unit weight of adsorbent and the unadsorbed phenolic compounds concentration in solution at equilibrium. $K_{L}(\mathrm{~L} / \mathrm{mg})$ is the affinity of the sorbate for binding sites, also defined as the Langmuir constant, and $q_{\max }(\mathrm{mg} / \mathrm{g})$ is the maximum adsorption capacity when the surface is fully covered with phenolic compounds. The linearized form is represented as follows:

$$
\frac{C_{e}}{q_{e}}=\frac{1}{K_{L} q_{\max }}+\frac{C_{e}}{q_{\max }}
$$

The plot of $C_{e} / q_{e}$ against $C_{e}$ should give a straight line with slope $1 / q_{\max }$ and intercept $1 / K_{L} q_{\max }$.

The Langmuir isotherm is based on the assumption that the adsorbent is a two-dimensional array of energetically homogenous sites, in which only one molecule per site may be adsorbed, and interactions between any of the adsorbed molecules are also excluded. Consequently, the adsorption process has a monolayer nature. As evident in Figure 6 and table here reported, the Langmuir isotherm model fits the experimental data remarkably well for both the phenolic compounds tested $\left(R^{2} 4\right.$-NP $=0.98$ and $R^{2} \mathrm{Ph}=0.92$ ). 
From the fitting parameters, the parameters of the Langmuir model are calculated. A high $q_{\max }$ of $25 \mathrm{mg} / \mathrm{g}$ for 4-NP and $14.29 \mathrm{mg} / \mathrm{g}$ for Ph was found.

A dimensionless parameter $R_{L}$ was calculated for different concentrations of phenolic compounds. This parameter, called equilibrium parameter, is defined as

$$
R_{L}=\frac{1}{1+K_{L} C_{0}}
$$

$R_{L}$ value indicates the type of isotherm to be irreversible $\left(R_{L}=0\right)$, favorable $\left(0<R_{L}<1\right)$, linear $\left(R_{L}=1\right.$, or unfavorable $R_{L}>1$ ) [36-39]. The results reported in the table at the bottom of Figure 6, revealed that the Langmuir adsorption is favorable for all the studied cases.

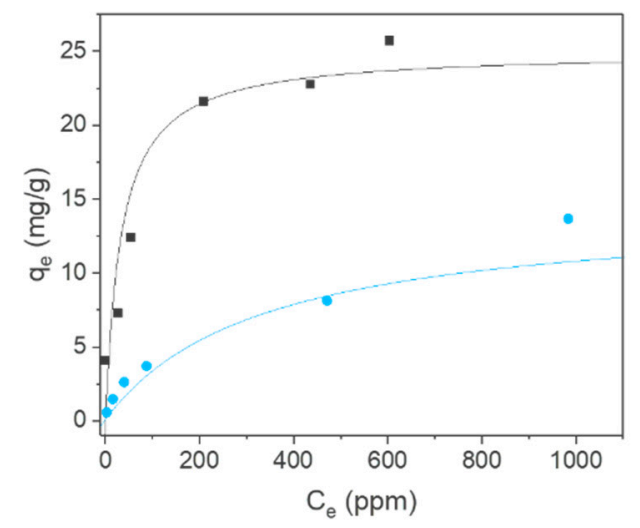

\begin{tabular}{ccccc}
\hline $\begin{array}{c}\text { Phenolic } \\
\text { compound }\end{array}$ & $\begin{array}{c}q_{\max } \\
(\mathrm{mg} / \mathrm{g})\end{array}$ & $\begin{array}{c}K_{L} \\
(\mathrm{~L} / \mathrm{g})\end{array}$ & $\boldsymbol{R}^{2}$ & $\boldsymbol{R}_{L}$ \\
\hline & & & & $0.02\left(\mathrm{C}_{0}=1600 \mathrm{ppm}\right)$ \\
$4-\mathrm{NP}$ & 25 & 0.03 & 0.98 & $0.07\left(\mathrm{C}_{0}=400 \mathrm{ppm}\right.$ \\
& & & & $0.14\left(\mathrm{C}_{0}=200 \mathrm{ppm}\right)$ \\
& & & & $0.57\left(\mathrm{C}_{0}=25 \mathrm{ppm}\right.$ \\
& & & & $0.22\left(\mathrm{C}_{0}=1119.9 \mathrm{ppm}\right)$ \\
$\mathrm{Ph}$ & 14.29 & 0.03 & 0.92 & $0.75\left(\mathrm{C}_{0}=110.1 \mathrm{ppm}\right)$ \\
& & & & $0.85\left(\mathrm{C}_{0}=58.4 \mathrm{ppm}\right)$ \\
& & & & $0.98\left(\mathrm{C}_{0}=6.3 \mathrm{ppm}\right)$ \\
\hline
\end{tabular}

Figure 6. Fitting of experimental data with Langmuir isotherm model for 4-NP (black squares) and Ph (blue circles). The table reports calculated values from Equations (3)-(5).

The adsorption of 4-NP and phenol on PDMS/MWNT ${ }_{\text {ox }}$ sponges were also studied with the Freundlich isotherm, which can be expressed as

$$
q_{e}=K_{F} C_{e}^{\frac{1}{n}}
$$

where $K_{F}$ is the Freundlich constant that shows adsorption capacity of adsorbent, and $n$ is a measure of intensity of adsorption. The equation can be expressed also by logarithmic form as

$$
\log q_{e}=\log K_{F}+\frac{1}{n} \log C_{e}
$$

The plot of $\log q_{\mathrm{e}}$ against $\log C_{e}$ should give a straight line with slope $1 / n$.

The Freundlich isotherm assumed that the adsorption occurs on heterogenous sites with non-uniform distribution of energy level. The model describes reversible adsorption, and is not restricted to the formation of a monolayer. Also, this theoretical model fits the experimental data remarkably well for both the phenolic compounds, as clearly visible in Figure 7, and by $R^{2}$ values reported in the table at the bottom of the figure. Similarly, as observed for Langmuir model, dimensionless parameter $\mathrm{n}$ shows a value between 1 and 10 in the whole tested concentration range, suggesting that the adsorption process of phenolic compounds is favorable for the tested concentrations [36,40]. 


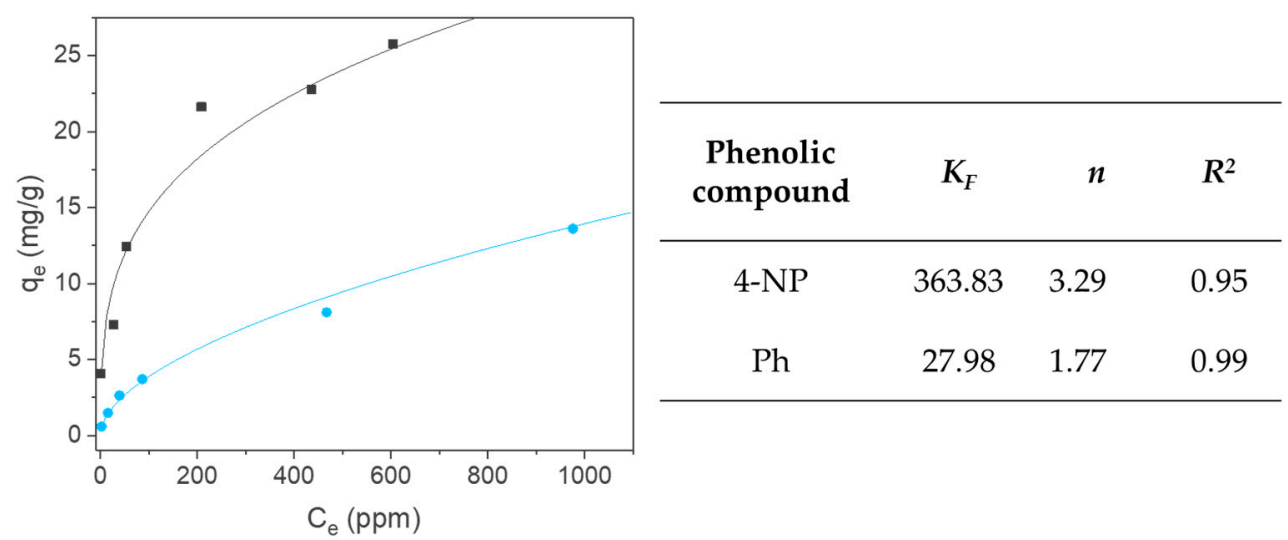

Figure 7. Fitting of experimental data with Freundlich isotherm model for 4-NP (black squares) and Ph (blue circles). The table reports calculated values from Equations (6) and (7).

As observed, both Langmuir and Freundlich models fit the experimental data, suggesting the possibility of monolayer phenolic compounds formation on $\mathrm{MWNT}_{\mathrm{ox}}$ surfaces with heterogenous sites. This phenomenon is not rare, as similar findings were already reported in literature $[39,41-43]$ and could be explained by understanding the surface chemistry composition of $\mathrm{MWNTs}_{\mathrm{ox}}$ entrapped on the surface of PDMS/MWNT ${ }_{\text {ox }}$ sponge. After the oxidation process, different chemical moieties with different abundances and non-uniform distribution are introduced on MWNT surfaces. This could cause differences in the energy level of the active sites available on the PDMS/MWNT ${ }_{\text {ox }}$ sponge surface, thus affecting the adsorption capacity. Active sites with higher energy levels tend to form heterolayer phenolic compound coverage with robust support from strong chemical bonding, while active sites with lower energy levels will induce monolayer coverage, due to electrostatic forces [39,41-43].

Table 1. Langmuir and Freundlich constants for phenolic compound adsorption from various absorbents reported in literature.

\begin{tabular}{|c|c|c|c|c|c|c|}
\hline Adsorbent & Adsorbate & $q_{\max }(\mathrm{mg} / \mathrm{g})$ & $K_{L}(\mathrm{~L} / \mathrm{g})$ & $K_{F}$ & $n$ & References \\
\hline \multirow{2}{*}{$\mathrm{PDMS}_{\mathrm{MWNTs}} \mathrm{Mx}_{\mathrm{O}}$} & 4-Nitrophenol & 25 & 0.03 & 363.83 & 3.29 & \multirow[b]{2}{*}{ This work } \\
\hline & Phenol & 14.29 & 0.03 & 27.98 & 1.77 & \\
\hline Resin AP-246 & Phenol & 0.071 & 0.584 & 0.112 & 0.35 & [42] \\
\hline Activated coal & Phenol & 1.84 & 0.065 & 0.79 & 0.79 & [42] \\
\hline Hydroxyapatite & Phenol & & & 0.37 & 1.66 & [44] \\
\hline Resin OC-1074 & Phenol & 0.043 & 0.445 & 0.0053 & 0.16 & [42] \\
\hline Coconut shell & Phenol & 205.84 & 3.91 & 37.11 & 3.66 & [45] \\
\hline MWNT-COOH & 4-nitrophenol & 256.41 & 0.05 & 23.15 & 1.34 & [46] \\
\hline
\end{tabular}

The obtained results were compared with different types of sorbent used for removal of phenolic compounds (Table 1). As evident the here-studied adsorbent evidenced a good adsorption capacity for both the adsorbates with higher and lower affinity with the PDMS/MWNT ${ }_{\text {ox }}$ sponge. The highest values reported in literature were achieved with coconut shells and $\mathrm{MWNT}_{\text {ox }}$ powder [46]. Their maximum adsorption capacity, $q_{\max }$, is almost one order of magnitude higher compared to that obtained in the present study, but it should be considered that herein, the adsorption capacities are calculated per gram of sponge and not per gram of $\mathrm{MWNT}_{\mathrm{ox}}$. With the consideration that the removal of phenolic compounds is attributed solely to the $\mathrm{MWNTs}_{\mathrm{ox}}$ present in the sponge (as demonstrated by adsorption kinetic studies, Figure 4), the $q_{\max }$ calculated per gram of MWNT is $374.6 \mathrm{mg} / \mathrm{g}$ for 4-NP, and $216.87 \mathrm{mg} / \mathrm{g}$ for phenol, thus reaching higher values than in [45,46]. Moreover, the here-proposed materials have the additional advantages of being user-friendly and easy to recover after adsorption processes. 
More in details, in a real application, the use of other proposed materials requires post-treatment processes (e.g., filtration, centrifugation) to remove the adsorbent from the aqueous solution after the uptake process. In the current study, $\mathrm{MWNTs}_{\mathrm{ox}}$ are entrapped in a macroporous polymeric sponge, easy to manipulate and separate, thus offering significant advantages in terms of costs and usability with respect to other approaches.

\subsection{Adsorption Kinetic Studies}

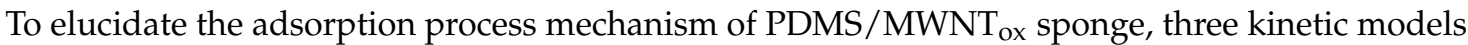
were used to test the experimental data, i.e., the pseudo-first order equation, the pseudo-second order equation, and the intraparticle diffusion equation. All the studies were performed in a solution containing $0.18 \mathrm{mM}$ of 4-nitrophenol or phenol in the presence of the same amount of adsorbent phase.

\subsection{The Pseudo-First Order and Pseudo-Second Order Kinetic Model}

The pseudo-first order kinetic model is more suitable for low concentrations of solute. The pseudo-first order equation is

$$
\ln \left(q_{e}-q_{t}\right)=\ln q_{e}-k_{1} t
$$

where $q_{e}$ and $q_{t}$ refer to the amount of phenolic compounds adsorbed $(\mathrm{mg} / \mathrm{g})$ at equilibrium and at any time, $t(\mathrm{~h})$, respectively, and $k_{1}\left(\mathrm{~h}^{-1}\right)$ is the equilibrium rate constant of pseudo-first order sorption. The plot of $\ln \left(q_{e}-q_{t}\right)$ against $\mathrm{t}$ should give a straight line with slope $-K_{1}$ and intercept $\ln q_{e}$, as can be seen in Figure 8. The calculated parameters are reported in the table. The correlation coefficient for 4-NP and Ph were 0.7 and 0.89 , respectively, and the relative calculated value of $q_{e}\left(q_{(e, c a l)}\right)$ were in both cases smaller than experimental ones $\left(q_{(e, e x p)}\right)$. The fitting results indicated that the experimental data did not agree well with this model.

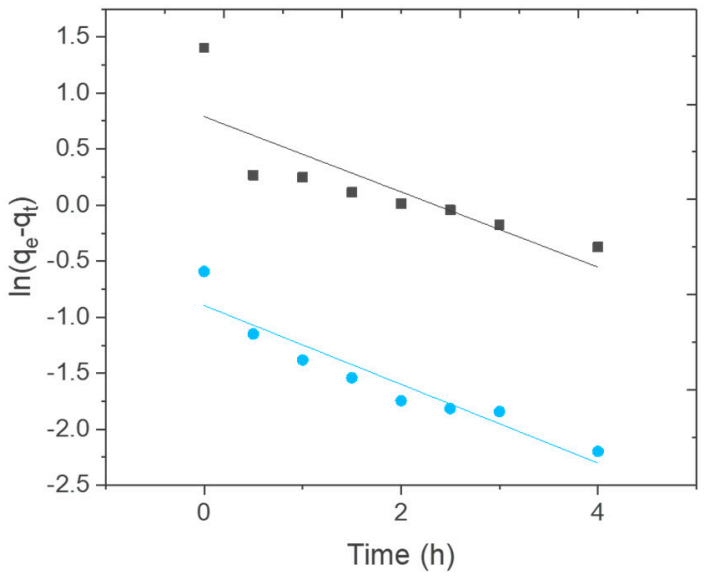

\begin{tabular}{ccc}
\hline $\begin{array}{c}\text { Phenolic } \\
\text { compound }\end{array}$ & $4-N P$ & $P h$ \\
\hline $\boldsymbol{q}_{(e, \text { exp })}(\mathbf{m g} / \mathrm{g})$ & 4.07 & 0.55 \\
$\boldsymbol{q}_{(e, \text { cal })}(\mathbf{m g} / \mathrm{g})$ & 2.2 & 0.41 \\
$K_{1}\left(\mathbf{h}^{-1}\right)$ & 0.33 & 0.35 \\
$\boldsymbol{R}^{2}$ & 0.7 & 0.89 \\
\hline
\end{tabular}

Figure 8. Application of pseudo-first order adsorption model for the adsorption of 4-NP (black square) and phenol (blue circles) onto PDMS/MWNT ${ }_{\text {ox }}$ sponges. The table reports the calculated values from Equation (8).

The pseudo-second order equation is dependent on the amount of the solute adsorbed on the surface of adsorbent, and the amount adsorbed at equilibrium, and is expressed in the form

$$
\frac{t}{q_{t}}=\frac{1}{k_{2} q_{e}^{2}}+\frac{t}{q_{e}}
$$

where $k_{2}$ is the rate constant of pseudo-second order equation, $q_{t}, q_{e}$ and $t$ have the same meaning as that in pseudo-first order equation. From the slope and the intercept of the plot of $t / q_{t}$ versus $t$ (Figure 9), the rate constant $\left(k_{2}\right)$ and the equilibrium adsorption capacity $\left(q_{e}\right)$ can be obtained. As 
observable in the table reported in Figure 8, the correlation coefficients $\left(R^{2}\right)$ were higher than 0.99 for both the tested phenolic compounds, and the calculated $q_{e}$ values are close to the experimental ones. These findings suggest that pseudo-second order model fits, remarkably well, the experimental data, making it suitable to explain the kinetics for the adsorption of phenolic compounds onto the PDMS/MWNT ${ }_{\text {ox }}$ sponge. In more detail, it suggests that the chemical sorption in the adsorption process [39] is mainly due to $\pi-\pi$ interactions, as previously demonstrated with isotherm studies.

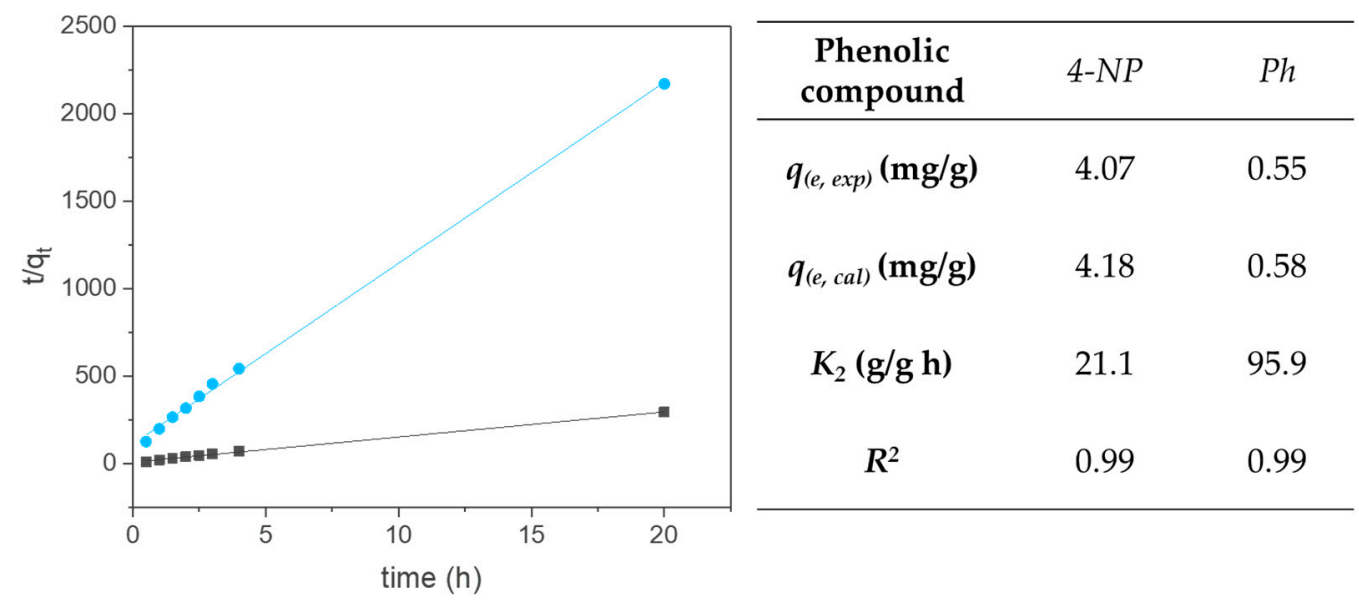

Figure 9. Application of pseudo-second order adsorption model for the adsorption of 4-NP

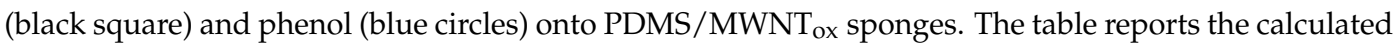
values from Equation (9).

\subsection{The Intraparticles Diffusion Model}

Although the pseudo-first order and the pseudo-second order models can explain the adsorption process, none of them could identify the diffusion mechanisms, and so then the intraparticle diffusion model was also used to analyze and elucidate the diffusion mechanism. The intraparticle diffusion equation can be written in the following form:

$$
q_{t}=k_{p} t^{1 / 2}+C
$$

where $k_{p}$ is the rate constant of intraparticle diffusion model, $C$ is a constant for any experiment $(\mathrm{mg} / \mathrm{g})$, and $q_{t}$ has the same meaning as that in Equation (9). By plotting $q_{t}$ versus $t^{1 / 2}$ curves, two linear ranges were obtained for both the tested phenols, thus indicating the occurrence of at least two diffusion steps during the adsorption process.

As shown in Figure 10, from the slope of each linear curve, $k_{p}$ values can be obtained. From the extrapolation of the first step in the curve to the time axis, the intercept $C$ could be obtained [47]. As seen in table reported in Figure 10, most of the correlation coefficients are higher than 0.97 for both the phenolic compounds tested, which suggested that the adsorption of phenolic compounds by the PDMS/MWNT ${ }_{\text {ox }}$ sponge fit this model well. The slope of the linear portion indicated the rate of diffusion; a larger $k$ corresponds to a faster diffusion process. Hence, $k_{1}>k_{2}$ (with $k_{1}$ and $k_{2}$ representing $k_{p}$ values for step I and II, respectively) indicated the free path available for diffusion became smaller, thus leading to the reduction rate in the diffusion process. In more detail, it could be hypothesized that the external surface adsorption or diffusion in macropores occurred at the first step, until the outer part reached saturation. After this process, the phenolic compounds entered into less accessible pores, or in small portions between two adjacent carbon nanotubes, so the diffusion resistance increased, and the diffusion rate decreased. Consequently, the second step was the final equilibrium step for which the adsorbed molecules move slowly from larger pores to smaller pores, 
and in regions between adjacent MWNTs, causing a slow adsorption rate [48]. The interpretation of this phenomena was already reported in literature $[47,49,50]$.

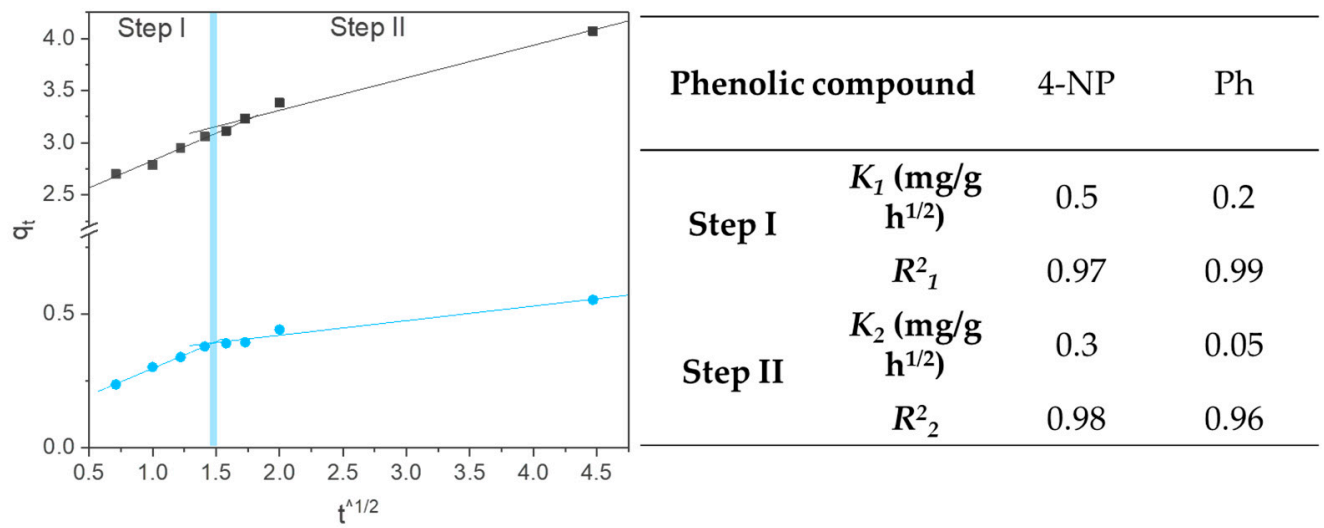

Figure 10. Application of intraparticle diffusion model for the adsorption of 4-NP (black square) and

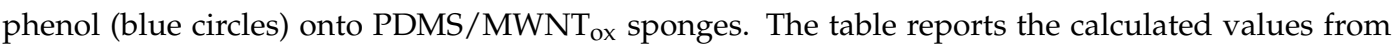
Equation (10).

\subsection{Reusability Studies}

Reusability studies were performed to check the recyclability of the PDMS/MWNT ox $_{\text {spongeous }}$ materials, and better elucidate the mechanism of adsorption. After a first adsorption process, three different sponges were washed in three different solutions: water, $5 \%$ acetic acid $(\mathrm{pH}=2.4)$, and alkaline water $(\mathrm{pH}=12)$, and used for another adsorption process. The experiments were performed for both 4-NP and $\mathrm{Ph}$. In all cases, the washing solutions were heated at $70{ }^{\circ} \mathrm{C}$, it is well known in fact that $\pi-\pi$ interactions are weaker at this temperature [51]. After acetic acid treatment, the PDMS/MWNT ${ }_{\text {ox }}$ sponges demonstrated a recovery of the original uptake of $\sim 96 \%$ for 4 -NP and $~ 98 \%$ for $\mathrm{Ph}$, suggesting that after this procedure, most of the adsorption sites are recovered due to the desorption of phenolic compounds. The washing procedure with warm water evidenced a recovery of lower than $8 \%$ for both the tested phenolic compounds, suggesting strong interactions between these species and the PDMS/MWNT $\mathrm{Mx}_{\text {ox }}$ sponge are present. A recovery of $\sim 63 \%$ for $4-\mathrm{NP}$ and $52 \%$ for $\mathrm{Ph}$ was obtained after washing at $\mathrm{pH}=12$, probably because at this $\mathrm{pH}$, most of the oxygen-containing moieties on $\mathrm{MWNT}_{\text {ox }}$ surface and phenolic compounds are in the deprotonated form, favoring the desorption of part of the phenols through electrostatic repulsion.

Moreover, as already reported in literature, the higher recovery of binding sites in the presence of organic acids can be confirmed, as the adsorption is held by the sorbent through chemisorption process for both the tested phenolic compounds [39].

\subsection{Removal of Phenolic Compound from Olive Mill Wastewater}

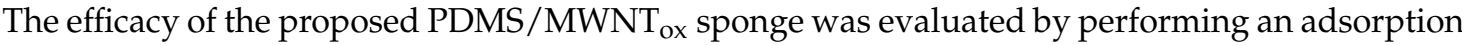
test in a complex matrix, such as oil mill wastewater (OMW). Material corresponding to $1.2 \%$ in weight of adsorbent was tested at ambient temperature, under stirring and $24 \mathrm{~h}$ of contact time with OMW, in which the amount of phenolic compound was equal to 1250.9 ppm, calculated with the Folin-Ciocalteu assay. The results showed that with this amount of PDMS/MWNT ox $_{\text {sponge, }}$ we obtained an elimination of $32.3 \%$ of total phenolic compounds, suggesting the possibility to use the material as an adsorbent phase for phenolic compounds in complex matrices. A proper decontamination of OMW could be obtained by the increase of the adsorbent phase or the number of adsorption cycles. 


\section{Conclusions}

In conclusion, the present work describes the formation of a nanocomposite sponge made of PDMS and oxidized MWNTs for the removal of phenolic compounds from water. The MWNT loading was performed during the fabrication of the sponge without the use of solvent and/or complex procedures. The oxidation of MWNTs was necessary to increase sponges' affinity toward phenolic compounds, and was performed directly on the as-produced foam, simplifying the post-treatment washing procedure and speeding up the whole process. The as-prepared materials showed high adsorption capacity with different affinity towards different phenolic compounds. As demonstrated, this is basically due to the different $\pi-\pi$ electron donor-acceptor interactions between adsorbate and adsorbent, depending on the different type and number of substituents on aromatic rings of phenolic compounds. The formation of an heterogenous monolayer during the adsorption process onto PDMS/MWNT $\mathrm{Ox}_{\text {sponge }}$ surface was demonstrated by Langmuir and Freundlich isotherm studies. The pseudo-second order kinetic model was found to represent the adsorption kinetic process with higher correlation coefficients than the pseudo-first order kinetic model, confirming the chemical interaction between the phenolic compounds and the spongeous material. In addition, two different steps for adsorption procedure were identified with the intraparticle diffusion model, probably depending on the presence of pores with different sizes, and on the low accessibility of binding sites between adjacent MWNTs.

The entrapment of MWNTs ${ }_{\text {ox }}$ adsorbent in a porous polymeric matrix represents a significant advantage with respect to other approaches presented for the adsorption of phenolic compounds. Usually, post-treatment processes, such as filtration or centrifugation, are required to remove the (nano)adsorbent phase after the adsorption process, increasing time and costs of the treatment. These problems are avoided with the here-proposed approach. Moreover, the here-prepared sponges evidenced good adsorption capacity, suggesting that the synthetic pathway did not significantly affect adsorption capacity of MWNTs. The proposed method of preparation could be also extended to other (nano)adsorbents to facilitate the handling and safe disposal of the nanomaterials.

To further demonstrate the adsorption capacity of the materials, a complex matrix, such as OMW sample, was treated with the nanocomposite to remove phenolic compounds, demonstrating their effective removal, and suggesting their possible use for the treatment of wastewater. Moreover, the surface material could be regenerated towards an acidic treatment, thus decreasing the costs of production in wastewater treatment application.

Supplementary Materials: The following are available online at http:/ /www.mdpi.com/2079-4991/8/5/334/s1.

Author Contributions: Conceptualization, A.T.; Methodology, A.T.; Validation, A.T., C.M., A.G.M., E.M. and G.M.; Investigation, A.T., A.G.M.; Resources, A.T., C.M. and G.M.; Writing-Original Draft Preparation, A.T.; Writing-Review \& Editing, A.T., C.M., E.M., A.G.M. and G.M.; Supervision, A.T.; Funding Acquisition, A.T.

Funding: This research was funded by Fondazione CARIPUGLIA, project: "Materiali innovativi porosi nanocompositi per la rimozione e il recupero di composti fenolici da acque di vegetazione olearie" and Cohesion fund 2007-2013-APQ Ricerca Regione Puglia "Programma regionale a sostegno della specializzazione intelligente e della sostenibilità sociale ed ambientale-FutureInResearch" under Grant No. 9EC1495 (Ultrasensitive sensor for food analysis).

Acknowledgments: We thank Ilaria de Cataldo for her technical help in adsorption measurements.

Conflicts of Interest: The authors declare no conflict of interest.

\section{References}

1. Busca, G.; Berardinelli, S.; Resini, C.; Arrighi, L. Technologies for the removal of phenol from fluid streams: A short review of recent developments. J. Hazard. Mater. 2008, 160, 265-288. [CrossRef] [PubMed]

2. Kavlock, R.J.; Oglesby, L.A.; Hall, L.L.; Fisher, H.L.; Copeland, F.; Logsdon, T.; Ebron-McCoy, M. In vivo and in vitro structure-dosimetry-activity relationships of substituted phenols in developmental toxicity assays. Reprod. Toxicol. 1991, 5, 255-258. [CrossRef] 
3. Pimentel, M.; Oturan, N.; Dezotti, M.; Oturan, M.A. Phenol degradation by advanced electrochemical oxidation process electro-Fenton using a carbon felt cathode. Appl. Catal. B Environ. 2008, 83, 140-149. [CrossRef]

4. Polcaro, A.M.; Vacca, A.; Palmas, S.; Mascia, M. Electrochemical treatment of wastewater containing phenolic compounds: Oxidation at boron-doped diamond electrodes. J. Appl. Electrochem. 2003, 33, 885-892. [CrossRef]

5. Comninellis, C.; Pulgarin, C. Electrochemical oxidation of phenol for wastewater treatment using $\mathrm{SnO}_{2}$, anodes. J. Appl. Electrochem. 1993, 23, 108-112. [CrossRef]

6. El-Ashtoukhy, E.-S.Z.; El-Taweel, Y.A.; Abdelwahab, O.; Nassef, E.M. Treatment of Petrochemical Wastewater Containing Phenolic Compounds by Electrocoagulation Using a Fixed Bed Electrochemical Reactor. Int. J. Electrochem. Sci. 2013, 8, 1534-1550.

7. Adhoum, N.; Monser, L. Decolourization and removal of phenolic compounds from olive mill wastewater by electrocoagulation. Chem. Eng. Process. Process Intensif. 2004, 43, 1281-1287. [CrossRef]

8. Golbaz, S.; Jafari, A.J.; Rafiee, M.; Kalantary, R.R. Separate and simultaneous removal of phenol, chromium, and cyanide from aqueous solution by coagulation/precipitation: Mechanisms and theory. Chem. Eng. J. 2014, 253, 251-257. [CrossRef]

9. Vatai, T.; Škerget, M.; Knez, Ž. Extraction of phenolic compounds from elder berry and different grape marc varieties using organic solvents and/or supercritical carbon dioxide. J. Food Eng. 2009, 90, $246-254$. [CrossRef]

10. Lafka, T.-I.; Sinanoglou, V.; Lazos, E.S. On the extraction and antioxidant activity of phenolic compounds from winery wastes. Food Chem. 2007, 104, 1206-1214. [CrossRef]

11. Adler, P.R.; Arora, R.; El Ghaouth, A.; Glenn, D.M.; Solar, J.M. Bioremediation of Phenolic Compounds from Water with Plant Root Surface Peroxidases. J. Environ. Qual. 1994, 23, 1113. [CrossRef]

12. Liu, Y.; Zeng, Z.; Zeng, G.; Tang, L.; Pang, Y.; Li, Z.; Liu, C.; Lei, X.; Wu, M.; Ren, P.; et al. Immobilization of laccase on magnetic bimodal mesoporous carbon and the application in the removal of phenolic compounds. Bioresour. Technol. 2012, 115, 21-26. [CrossRef] [PubMed]

13. Luke, A.K.; Burton, S.G. A novel application for Neurospora crassa: Progress from batch culture to a membrane bioreactor for the bioremediation of phenols. Enzym. Microb. Technol. 2001, 29, 348-356. [CrossRef]

14. Peiró, A.M.; Ayllón, J.A.; Peral, J.; Doménech, X. $\mathrm{TIO}_{2}$-photocatalyzed degradation of phenol and ortho-substituted phenolic compounds. Appl. Catal. B Environ. 2001, 30, 359-373. [CrossRef]

15. Teh, C.M.; Mohamed, A.R. Roles of titanium dioxide and ion-doped titanium dioxide on photocatalytic degradation of organic pollutants (phenolic compounds and dyes) in aqueous solutions: A review. J. Alloys Compd. 2011, 509, 1648-1660. [CrossRef]

16. Wu, C.; Liu, X.; Wei, D.; Fan, J.; Wang, L. Photosonochemical degradation of Phenol in water. Water Res. 2001, 35, 3927-3933. [CrossRef]

17. Zhao, X.; Shi, Y.; Wang, T.; Cai, Y.; Jiang, G. Preparation of silica-magnetite nanoparticle mixed hemimicelle sorbents for extraction of several typical phenolic compounds from environmental water samples. J. Chromatogr. A 2008, 1188, 140-147. [CrossRef] [PubMed]

18. Wu, X.; Zhang, Y.; Han, T.; Wu, H.; Guo, S.; Zhang, J. Composite of graphene quantum dots and $\mathrm{Fe}_{3} \mathrm{O}_{4}$ nanoparticles: Peroxidase activity and application in phenolic compound removal. RSC Adv. 2014, 4, 3299-3305. [CrossRef]

19. Ozkaya, B. Adsorption and desorption of phenol on activated carbon and a comparison of isotherm models. J. Hazard. Mater. 2006, 129, 158-163. [CrossRef] [PubMed]

20. Daifullah, A.A.M.; Girgis, B.S. Removal of some substituted phenols by activated carbon obtained from agricultural waste. Water Res. 1998, 32, 1169-1177. [CrossRef]

21. Dąbrowski, A.; Podkościelny, P.; Hubicki, Z.; Barczak, M. Adsorption of phenolic compounds by activated carbon-A critical review. Chemosphere 2005, 58, 1049-1070. [CrossRef] [PubMed]

22. Li, A.; Zhang, Q.; Zhang, G.; Chen, J.; Fei, Z.; Liu, F. Adsorption of phenolic compounds from aqueous solutions by a water-compatible hypercrosslinked polymeric adsorbent. Chemosphere 2002, 47, 981-989. [CrossRef]

23. Li, A.; Zhang, Q.; Chen, J.; Fei, Z.; Long, C.; Li, W. Adsorption of phenolic compounds on Amberlite XAD-4 and its acetylated derivative MX-4. React. Funct. Polym. 2001, 49, 225-233. [CrossRef] 
24. Bilgili, M.S. Adsorption of 4-chlorophenol from aqueous solutions by xad-4 resin: Isotherm, kinetic, and thermodynamic analysis. J. Hazard. Mater. 2006, 137, 157-164. [CrossRef] [PubMed]

25. Ahmaruzzaman, M. Adsorption of phenolic compounds on low-cost adsorbents: A review. Adv. Colloid Interface Sci. 2008, 143, 48-67. [CrossRef] [PubMed]

26. Yang, K.; Wu, W.; Jing, Q.; Zhu, L. Aqueous Adsorption of Aniline, Phenol, and their Substitutes by Multi-Walled Carbon Nanotubes. Environ. Sci. Technol. 2008, 42, 7931-7936. [CrossRef] [PubMed]

27. Lin, D.; Xing, B. Adsorption of phenolic compounds by carbon nanotubes: Role of aromaticity and substitution of hydroxyl groups. Environ. Sci. Technol. 2008, 42, 7254-7259. [CrossRef] [PubMed]

28. Chen, W.; Duan, L.; Zhu, D. Adsorption of Polar and Nonpolar Organic Chemicals to Carbon Nanotubes. Environ. Sci. Technol. 2007, 41, 8295-8300. [CrossRef] [PubMed]

29. Pan, B.; Xing, B. Adsorption Mechanisms of Organic Chemicals on Carbon Nanotubes. Environ. Sci. Technol. 2008, 42, 9005-9013. [CrossRef] [PubMed]

30. Turco, A.; Malitesta, C.; Barillaro, G.; Greco, A.; Maffezzoli, A.; Mazzotta, E. A magnetic and highly reusable macroporous superhydrophobic/superoleophilic PDMS/MWNT nanocomposite for oil sorption from water. J. Mater. Chem. A 2015, 3, 17685-17696. [CrossRef]

31. Singleton, V.L.; Orthofer, R.; Lamuela-Raventós, R.M. Analysis of total phenols and other oxidation substrates and antioxidants by means of folin-ciocalteu reagent. Methods Enzymol. 1999, 299, 152-178. [CrossRef]

32. Avilés, F.; Cauich-Rodríguez, J.V.; Moo-Tah, L.; May-Pat, A.; Vargas-Coronado, R. Evaluation of mild acid oxidation treatments for MWCNT functionalization. Carbon 2009, 47, 2970-2975. [CrossRef]

33. Chiang, Y.-C.; Lin, W.-H.; Chang, Y.-C. The influence of treatment duration on multi-walled carbon nanotubes functionalized by $\mathrm{H}_{2} \mathrm{SO}_{4} / \mathrm{HNO}_{3}$ oxidation. Appl. Surf. Sci. 2011, 257, 2401-2410. [CrossRef]

34. Turco, A.; Primiceri, E.; Frigione, M.; Maruccio, G.; Malitesta, C. An innovative, fast and facile soft-template approach for the fabrication of porous PDMS for oil-water separation. J. Mater. Chem. A 2017, 5, 23785-23793. [CrossRef]

35. Ciccarelli, O.; Thomas, D.L.; De Vita, E.; Wheeler-Kingshott, C.A.M.; Kachramanoglou, C.; Kapoor, R.; Leary, S.; Matthews, L.; Palace, J.; Chard, D.; et al. Low Myo-inositol indicating astrocytic damage in a case series of neuromyelitis optica. Ann. Neurol. 2013, 74, 301-305. [CrossRef] [PubMed]

36. Dada, A.O.; Olalekan, A.P.; Olatunya, A.M.; Dada, O. Langmuir, Freundlich, Temkin and Dubinin-Radushkevich Isotherms Studies of Equilibrium Sorption of $\mathrm{Zn}^{2+}$ Unto Phosphoric Acid Modified Rice Husk. IOSR J. Appl. Chem. 2012, 3, 38-45. [CrossRef]

37. Ho, Y.S.; Huang, C.T.; Huang, H.W. Equilibrium sorption isotherm for metal ions on tree fern. Process Biochem. 2002, 37, 1421-1430. [CrossRef]

38. Athanassiou, A.; Fragouli, D.; Materials, S.; Italiano, I. Spent Coffee Bioelastomeric Composite Foams for the Removal of $\mathrm{Pb}^{2+}$ and $\mathrm{Hg}^{2+}$ from Water. ACS Sustain. Chem. Eng. 2016, 4, 5495-5502. [CrossRef]

39. Achak, M.; Hafidi, A.; Ouazzani, N.; Sayadi, S.; Mandi, L. Low cost biosorbent "banana peel" for the removal of phenolic compounds from olive mill wastewater: Kinetic and equilibrium studies. J. Hazard. Mater. 2009, 166, 117-125. [CrossRef] [PubMed]

40. Tabatabai, M.A.; Sparks, D.L.; Goldberg, S. Equations and models describing adsorption processes in soils. In Chemical Processes in Soils; Soil Science Society of America: Madison, WI, USA, 2005; pp. 489-517.

41. Nielsen, L.; Biggs, M.J.; Skinner, W.; Bandosz, T.J. The effects of activated carbon surface features on the reactive adsorption of carbamazepine and sulfamethoxazole. Carbon 2014, 80, 419-432. [CrossRef]

42. Vázquez, I.; Rodríguez-Iglesias, J.; Marañón, E.; Castrillón, L.; Álvarez, M. Removal of residual phenols from coke wastewater by adsorption. J. Hazard. Mater. 2007, 147, 395-400. [CrossRef] [PubMed]

43. Annadurai, G.; Juang, R.-S.; Lee, D.-J. Use of cellulose-based wastes for adsorption of dyes from aqueous solutions. J. Hazard. Mater. 2002, 92, 263-274. [CrossRef]

44. Lin, K.; Pan, J.; Chen, Y.; Cheng, R.; Xu, X. Study the adsorption of phenol from aqueous solution on hydroxyapatite nanopowders. J. Hazard. Mater. 2009, 161, 231-240. [CrossRef] [PubMed]

45. Mohd Din, A.T.; Hameed, B.H.; Ahmad, A.L. Batch adsorption of phenol onto physiochemical-activated coconut shell. J. Hazard. Mater. 2009, 161, 1522-1529. [CrossRef] [PubMed]

46. Arasteh, R.; Masoumi, M.; Rashidi, A.M.; Moradi, L.; Samimi, V.; Mostafavi, S.T. Adsorption of 2-nitrophenol by multi-wall carbon nanotubes from aqueous solutions. Appl. Surf. Sci. 2010, 256, 4447-4455. [CrossRef] 
47. Cheng, C.S.; Deng, J.; Lei, B.; He, A.; Zhang, X.; Ma, L.; Li, S.; Zhao, C. Toward 3D graphene oxide gels based adsorbents for high-efficient water treatment via the promotion of biopolymers. J. Hazard. Mater. 2013, 263, 467-478. [CrossRef] [PubMed]

48. Agnihotri, S.; Mota, J.P.B.; Rostam-Abadi, M.; Rood, M.J. Theoretical and Experimental Investigation of Morphology and Temperature Effects on Adsorption of Organic Vapors in Single-Walled Carbon Nanotubes. J. Phys. Chem. B 2006, 110, 7640-7647. [CrossRef] [PubMed]

49. Wu, F.-C.; Tseng, R.-L.; Juang, R.-S. Initial behavior of intraparticle diffusion model used in the description of adsorption kinetics. Chem. Eng. J. 2009, 153, 1-8. [CrossRef]

50. El Qada, E.N.; Allen, S.J.; Walker, G.M. Adsorption of Methylene Blue onto activated carbon produced from steam activated bituminous coal: A study of equilibrium adsorption isotherm. Chem. Eng. J. 2006, 124, 103-110. [CrossRef]

51. McGaughey, G.B.; Gagné, M.; Rappé, A.K. $\pi$-Stacking interactions. Alive and well in proteins. J. Biol. Chem. 1998, 273, 15458-15463. [CrossRef] [PubMed]

(C) 2018 by the authors. Licensee MDPI, Basel, Switzerland. This article is an open access article distributed under the terms and conditions of the Creative Commons Attribution (CC BY) license (http://creativecommons.org/licenses/by/4.0/). 